\title{
Verbascoside promotes apoptosis by regulating HIPK2-p53 signaling in human colorectal cancer
}


Qing $\mathrm{Ji}^{1}$, Yan Wang ${ }^{2}$ and Qi Li ${ }^{*}$

\begin{abstract}
Background: We investigated the role of the HIPK2-p53 signaling pathway in tumorigenesis and resistance to the drug Verbascoside (VB) in colorectal cancer (CRC), using in vivo and in vitro experiments.

Methods: Primary human CRC samples and normal intestinal tissues from patients were analyzed for HIPK2 expression by immunohistochemistry $(\mathrm{IHC})$ and its expression was correlated against patients' clinicopathological characteristics. Human CRC HCT-116 cells were implanted in BALB/c nude mice; mice with xenografted tumors were randomly administrated vehicle (control), 20, 40 , or $80 \mathrm{mg} / \mathrm{mL}$ VB, or $1 \mathrm{mg} / \mathrm{mL}$ fluorouracil (5-FU). HIPK2, p53, Bax, and $\mathrm{BCl}-2$ expression in these tumors were determined by $\mathrm{HC}$. In vitro effects of VB on CRC cell proliferation and apoptosis were measured by CCK-8 assay and flow cytometry; HIPK2, p53, p-p53, Bax, and Bcl-2 were measured by western blot.

Results: $I H C$ analysis for 100 human CRC tumor samples and 20 normal intestinal tissues, showed HIPK2 expression to inversely correlate with Dukes stage and depth of invasion in CRC $(P<0.05)$. In vivo, the inhibition rates of 20,40, and $80 \mathrm{mg} / \mathrm{mL}$ VB on CRC xenograft tumor weight were $42.79 \%, 53.90 \%$, and $60.99 \%$, respectively, and were accompanied by increased expression of HIPK2, p53, and Bax, and decreased $\mathrm{BCl}-2$ expression in treated tumors. In vitro, VB significantly inhibited proliferation of CRC cell lines HCT-116, HT-29, LoVo, and SW620, in a time- and dose-dependent manner. The apoptosis rates of 25,50 , and $100 \mu \mathrm{M}$ VB on HCT-116 cells were $10.83 \pm 1.28,11.25 \pm$ 1.54, and 20.19 $\pm 2.87 \%$, and on HT-29 cells were $18.92 \pm 6.12,21.57 \pm 4.05$, and $25.14 \pm 6.73 \%$, respectively. In summary, VB treatment significantly enhanced the protein expression of pro-apoptotic HIPK2, p53, p-p53, Bax, and decreased anti-apoptotic BCl-2 expression in CRC cells.

Conclusions: HIPK2 protein modulates the phosphorylation status of p53, and levels of Bax and BCl-2 in CRC. We also found that VB effectively activated the HIPK2-p53 signaling pathway, resulting in increased CRC cell apoptosis.
\end{abstract}

Keywords: Verbascoside, Homeodomain Interacting Protein Kinase 2, p53, apoptosis, colorectal cancer

\section{Background}

Colorectal cancer (CRC) is one of the most common malignancies in the world. With economic development and lifestyle changes, the incidence of CRC has been increasing yearly, with a significant rising rate. According to Global Cancer Statistics 2011, the incidence of CRC ranked third among male cancer patients and second among female cancer patients. In 2011, people who died from CRC accounted for $8 \%$ of all cancer deaths. It is the

\footnotetext{
*Correspondence: Izwf@hotmail.com

${ }^{\dagger}$ Equal contributors

'Department of Medical Oncology, Shuguang Hospital, Shanghai University of Traditional Chinese Medicine, Shanghai 201203, China

Full list of author information is available at the end of the article
}

fourth most common cause of cancer death [1]. In China, the rate of CRC incidence is increasing faster nationally than all other cancers. In the Shanghai area, CRC went from the fourth most common cancer in 1980s to the third most common in the 1990s [2] and by 2009 had become the second most common cancer in Shanghai [3].

Various factors contribute to CRC development, including intestinal mucosa losing normal growth control at the genetic level, leading to cell hyperproliferation. Most recent investigations of CRC tumorigenesis have therefore focused on functional abnormalities of relevant genes and their products. 
Homeodomain Interacting Protein Kinase 2 (HIPK2) is a member of the serine/threonineproteinkinase family, located inside the cell nucleus. It is a transcription mediator that interacts with homobox plastein. Reportedly, HIPK2 is associated with late embryogenesis, and neural, retinal, and muscle tissue development, and also participates in various aspects of tumorigenesis, including oncogene expression [4], apoptosis [5], angiogenesis [6], and multidrug resistance [7-9].

HIPK2 is a key regulator of numerous transcription factors, including p53, in DNA damage signaling pathways. HIPK2 co-localizes with p53in nucleosomes and phosphorylates Ser46 of p53. Using a microarray assay, Puca et al. found that HIPK2 knockdown in colon cancer cells led to the loss of target gene activation of wild-type p53 [10]. They also identified misfolding of p53 protein, and impaired p53-DNA binding and transcription of target genes. HIPK2 stimulates p300 and lys382-p53 for co-recruitment onto apoptosis promoters. By balancing p53 acetylation and deacetylation, HIPK2 regulates p53 apoptosis-promoting transcription activity [11]. McDonough et al. found HIPK2interacts with DAXX, a p53-binding protein, to inhibit binding with downstream effect or proteins, thus activating Ser46 phosphorylation and promoting p53 apoptotic signaling [12].

Verbascoside (VB), an active constituent of a Chinese traditional medical plant genus, Cistanche, has been shown to have anti-cancer activity in treating CRC, stomach [13], breast [14,15], prostate [16], melanoma [17], glioma [18], and other cancers. Cistanche, as a common clinical treatment for CRC, inhibits post-operative tumor recurrence, tumor invasion and metastasis, although the underlining mechanisms are not yet well understood.

In this study, we analyzed HIPK2 expression in primary tumor specimens of human $\mathrm{CRC}$, with particular regard to post-operative cancer recurrence, metastasis, and malignancy grades. We used a xenograft CRC mouse model to test the in vivo anti-tumor effect of $\mathrm{VB}$ and measured protein levels of HIPK2 and p53, and apoptosis-related gene products Bax and $\mathrm{Bcl}-2$. We also show that $\mathrm{VB}$ inhibits cell proliferation and promotes apoptosis in CRC by stimulating the HIPK2-p53 signaling pathway.

\section{Methods}

\section{Cell culture}

Human CRC cell lines HCT-116, LoVo, HT-29, and SW62were purchased from the Chinese Academy of Science. HCT-116 and LoVo were cultured in RPMI-1640 medium with $10 \%$ fetal bovine serum (FBS), HT-29 and SW620 were cultured in McCoy's 5A medium with $10 \%$ FBS. All cells were cultured with $100 \mu \mathrm{g} / \mathrm{mL}$ streptomycin (Invitrogen, Carlsbad, CA, USA) at $37^{\circ} \mathrm{C}$ in a $5 \% \mathrm{CO}_{2}$ humidified incubator (Thermo Fisher Scientific Inc., Waltham, MA, USA).

\section{Human tissue samples}

Human CRC tumor and normal tissue samples were collected from the General Surgery Department of our hospital from January 2011 to February 2012. All the experiments and animal care were approved by Shanghai Medical Experimental Animal Care Commission and in accordance with the Provision and General Recommendation of Chinese Experimental Animals Administration Legislation. The tissues were immediately frozen in liquid nitrogen and later preserved at ${ }^{-} 80^{\circ} \mathrm{C}$ for long-term storage. The use of all human tissue samples was approved by the Institutional Review Board of the Shuguang Hospital affiliated to Shanghai University of Traditional Chinese Medicine. We obtained consent from every patient, for the use of all human tissues used in this study.

\section{Animals}

BALB/c nude male mice, aged 4-6 weeks and weighing 18-20 g, were purchased from Sino-British SIPPR/BK lab Animal Co., Ltd (Shanghai, China, license No. SCXK 2008-0016). All animal protocols were approved by the Institutional Animal Use and Care Committee of Shanghai University of Traditional Chinese Medicine. Breeding conditions of the SPF Animal Laboratory were: free access to food and water, ventilation, humidity at 50-65\%, temperature at $22-24^{\circ} \mathrm{C}, 12 \mathrm{~h}$ of light/dark. The animal laboratory abided by related regulations of the Animal Ethics Committee.

\section{Immunohistochemical staining}

The human CRC tumor and normal tissue samples were paraffin embedded and serially sectioned. Tissue sections were processed by de-paraffining, rehydrating through an alcohol gradient, peroxidase clearing, antigen retrieval and blocking, antibody binding, DAB staining, washing with distilled water, hematoxylin staining, niacin alcohol differentiation, dilute ammonia bluing, incremental graded alcohol dehydration, xylene and conventional resin mounting. The primary antibody was rabbit-anti-human HIPK2 monoclonal antibody diluted by 1:50 (Abcam, Cambridge, MA, USA). The secondary biotin-labeled antibody was used at 1:200. For color development, streptavidin was labeled with horseradish peroxidase at 1:200. Under $400 \times$ magnification, five random fields were selected. Staining was assessed as: non-staining: 0 point; light brown: 1 point; brownish yellow: 2 points; and dark brown: 3points. Percentages of positive-stained cells were rated as: positive cells $\leq 5 \%$ : 0 point; $6-25 \%$ : 1 point; $26-50 \%: 2$ points; and $\geq 75 \%$ : 3 points. Points for staining and percentage were multiplied for a 10 -point scale: 0 point: negative (-), 1-3 points: weakly positive (+); 4-6 points: positive $(++)$; and $7-9$ points: strongly positive $(+++)$. 


\section{In vitro cell proliferation test}

Human CRC HCT-116, LoVo, HT-29, and SW620 cells in logarithmic growth phases were plated at $5 \times 10^{3}$ cells/well in 96-well plates; the next day, culture media was replaced with $200 \mu \mathrm{L}$ culture medium containing VB (purity $>98 \%$, purchased from Chendu Herb purify Biotechnology Co., Ltd, Chendu, China, serial number: 20100123), with concentrations of $12.5,25,50,100,150$, or $200 \mu \mathrm{M}$. For each concentration, 12 ventral orifices were set. After $24 \mathrm{~h}, 48 \mathrm{~h}$, and $72 \mathrm{~h}, 20 \mu \mathrm{L}$ of CCK-8 reagent (Dojindo Molecular Technologies, Inc., Tokyo, Japan) was added into each well. Four hours later, the light absorption value of each well at $490 \mathrm{~nm}$ was measured in a microplate reader (Bio-Rad Laboratories, Philadelphia, PA, USA). The inhibition rate of VB on the growth of CRC cells was calculated as the following equation: $\mathrm{GIR}=\left[1-\left(\mathrm{OD}_{\mathrm{N}}-\mathrm{OD}_{0}\right) /\left(\mathrm{OD}_{\mathrm{C}}-\mathrm{OD}_{0}\right)\right] \times 100 \%$; where $\mathrm{OD}_{0}$ was the absorbance value of the blank group, $\mathrm{OD}_{\mathrm{C}}$ the control group, and $\mathrm{OD}_{\mathrm{N}}$ groups with different doses of VB. The $\mathrm{IC}_{50}$ of VB was calculated using three independent experiments.

\section{Apoptosis measured by flow cytometry}

Rapid growing HCT-116 and HT-29 cells were treated with VBat different concentrations $(25,50$, or $100 \mu \mathrm{M})$ for $48 \mathrm{~h}$. Cells were then stained with $2 \mu \mathrm{L}$ Annexin-V and $2 \mu \mathrm{L}$ PI in $50 \mu \mathrm{L}$ of apoptosis reaction solution at $4^{\circ} \mathrm{C}$ for $30 \mathrm{~min}$. FACScan flow cytometry was used to detect apoptotic cells. Cell debris in different quadrants was calculated statistically. Cells in the upper right quadrant represented early apoptosis; cells in the lower right quadrant represented late apoptosis.

\section{In vivo xenografic $\mathrm{CRC}$ model}

HCT-116 cells $\left(2 \times 10^{6} /\right.$ mouse $)$ were injected subcutaneously into the right axilla of nude mice. Ten to 14 days later, when tumors formed, the nude mice with good growth state and unbroken tumors were used as tumor supply mice, and were then sacrificed. Tumors were dissected out under aseptic conditions, with necrotic and fibrous tissues removed. Fresh parts on the edge of tumors were cut into $1-\mathrm{mm}^{3}$ tumor blocks, which were implanted under the axillar skin of the right front legs of nude mice. With this method, three generations of mice were produced. The third-generation mice with unbroken transplanted tumor and sound growth state were sacrificed, and using the above-described method, the tumors were re-implanted and when they reached a size of $50-100 \mathrm{~mm}^{3}$, the tumor-bearing mice were randomly divided into five groups (six mice for each group): the control group (isometric normal saline), the low-, medium-, and high-dose VB groups (20, 40, and $80 \mathrm{mg} / \mathrm{kg} /$ day, respectively) and the fluorouracil (5-FU) group (1 mg/kg/day). VBand 5-FU were administered by tail vein injection. At days $1,4,7,10$, and 14, the long diameter (a) and the short diameter (b) of each tumor was measured, and tumor volume was calculated as $\left[\left(\mathrm{a} \times \mathrm{b}^{2}\right) / 2\right]$. After 14 days of treatment, mice were sacrificed and their tumors were dissected and connective tissues were removed. The tumors were

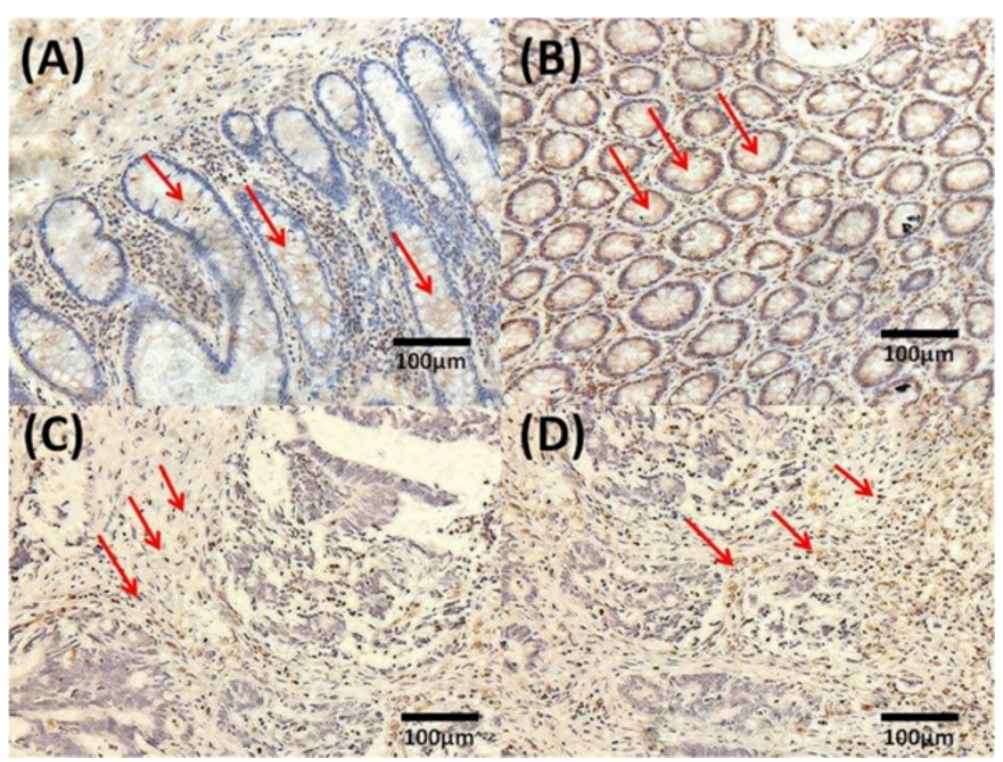

Figure 1 Representative HIPK2 IHC staining in normal and colorectal tumor tissue. Low HIPK2 protein expression in the normal tissue (-and +, Figure 1A), high HIPK2 protein expression in normal tissue $(++$ and +++ , Figure 1 B). Low HIPK2 protein expression in colorectal tumor tissue $(-$ and + , Figure 1C) and high expression incolorectal tumor tissue $(++$ and +++ , Figure 1 D). Magnification $\times 200$. 
Table 1 Differential expression of HIPK2 in cancerous and normal colorectal tissues

\begin{tabular}{lcccc}
\hline \multirow{2}{*}{ Group } & \multirow{2}{*}{$\boldsymbol{N}$} & \multicolumn{2}{c}{ Expression of HIPK2 (\%) } & \multirow{2}{*}{$\boldsymbol{P}$} \\
\cline { 2 - 4 } & & Low & High & \\
\hline Normal colorectal tissues & 20 & $40 \%$ & $60 \%$ & 0.003 \\
Colorectal cancer tissues & 100 & $74 \%$ & $26 \%$ & \\
\hline
\end{tabular}

weighed. We then calculated the tumor volume inhibition rates [(1- average tumor volume of the experimental group/average tumor volume of the control group) $\times$ $100 \%]$; and the tumor weight inhibition rates [(1 - average tumor weight of the experimental group/average tumor weight of the control group) $\times 100 \%]$.

\section{Protein extraction and western blot}

Western blot analyses were conducted as previously described $[19,20]$. Briefly, HCT-116 cells were treated by $\operatorname{VB}(25,50$, and $100 \mu \mathrm{M})$ for $48 \mathrm{~h}$, before being lysed and total protein was extracted. Protein samples were separated with $10 \%$ SDS-PAGE gel, transferred to a PVDF membrane with a Trans-Blot (Bio-Rad). The membrane was probed with primary antibodies (1: 1000 of anti-HIPK2, 1: 1000 of anti-P53, 1: 1000 of anti- p-p53, 1:1000 of anti-Bax, 1: 1000 of anti-Bcl-2, or 1: 4000 of anti- $\beta$-actin; Cell Signaling Technology, Danvers, MA, USA). The signal intensities of protein abundance were quantitatively analyzed by Image J.

\section{Statistical analysis}

Software SPSS18.0 was used for statistical data analysis. The data was expressed with $\mathrm{x} \pm \mathrm{s}$. If data met the homogeneity of variance of Gaussian distribution, we used oneway analysis of variance for statistical inference; otherwise, we used non-parametric tests. The test criterion $\alpha=0.05$, $P<0.05$ was considered statistically significant.

Table 2 Relationship between clinicopathological parameters and HIPK2 expression in human CRC

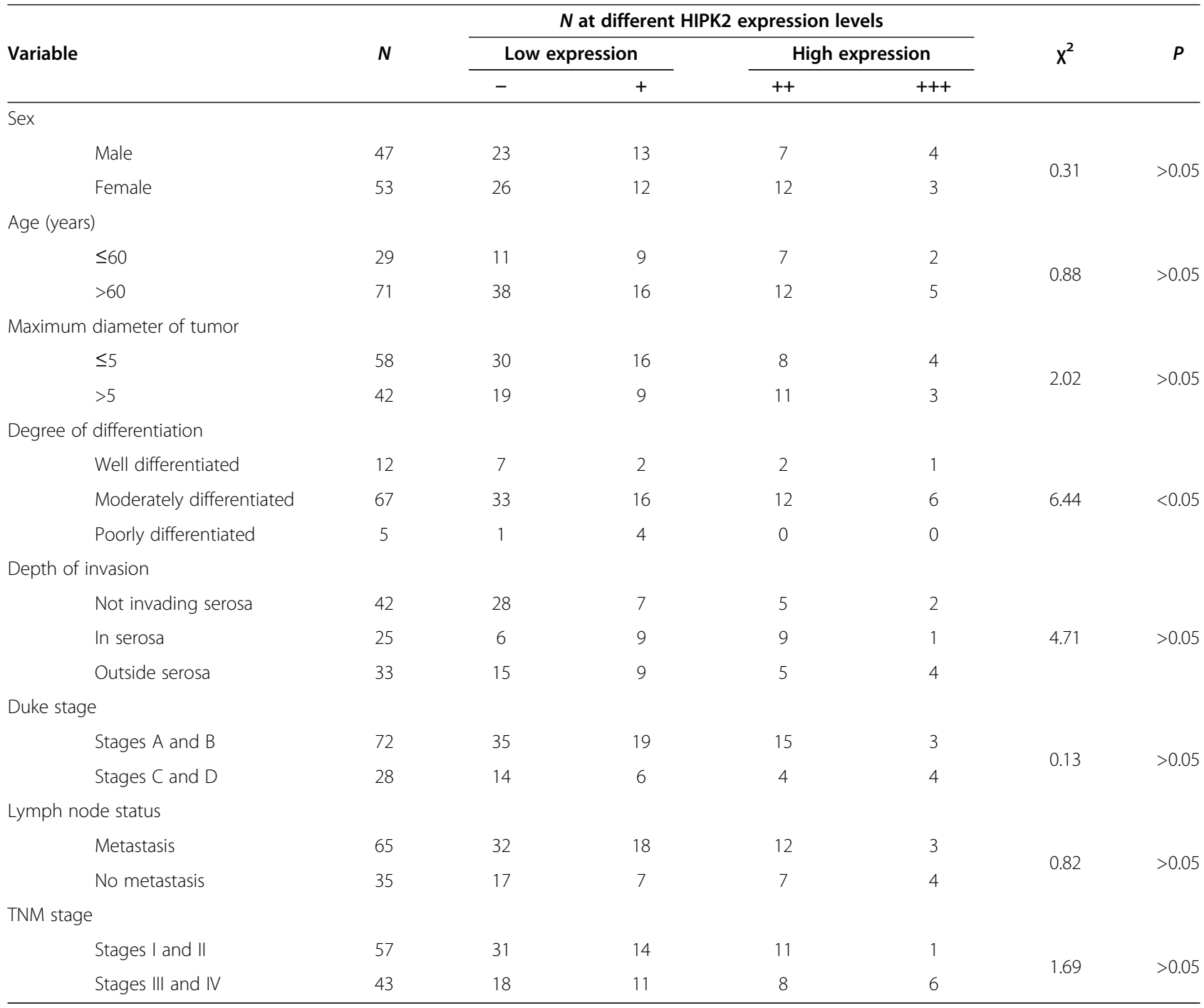




\section{Results}

HIPK2 protein levels and CRC clinicopathologic features are inversely associated

In 100 cases of human CRC cancer samples, 74 expressed low levels of HIPK2 protein (-and + , Figure 1A) and 26showed high expression (++ and +++ , Figure 1B). In 20 cases of normal colorectal cancer tissues, eight had low HIPK2 protein expression (-and +, Figure 1C) and 12had high expression $(++$ and +++ , Figure 1D). Expression of HIPK2 was significantly higher in normal tissues than in CRC tissues (Table 1). We further found that HIPK2 protein expression in human CRC significantly correlated with the degree of differentiation (Table 2). However, the HIPK2 expression levels were not significantly associated with sex, age, maximum tumor diameter, Dukes staging, degree of cancer infiltration, or number of metastasized lymph nodes.
Table 3 Effect of Verbascoside on expression levels of apoptosis-related proteins in CRC xenograft tumors

\begin{tabular}{lccccc}
\hline \multirow{2}{*}{ Groups } & \multirow{n}{n}{} & \multicolumn{4}{c}{ Relative protein expression level } \\
\cline { 3 - 6 } & & HIPK2 & P53 & Bax & Bcl-2 \\
\hline Control & 6 & $3.23 \pm 0.61$ & $11.70 \pm 2.08$ & $9.82 \pm 0.55$ & $17.43 \pm 1.50$ \\
$20 \mathrm{mg} / \mathrm{kg} \mathrm{VB}$ & 6 & $4.83 \pm 0.62$ & $14.59 \pm 0.90$ & $14.41 \pm 0.38$ & $14.08 \pm 1.04$ \\
$40 \mathrm{mg} / \mathrm{kg} \mathrm{VB}$ & 6 & $8.46 \pm 0.99$ & $17.60 \pm 1.40$ & $15.84 \pm 0.54$ & $11.93 \pm 0.93$ \\
$80 \mathrm{mg} / \mathrm{kg} \mathrm{VB}$ & 6 & $11.90 \pm 1.21$ & $23.10 \pm 2.10$ & $26.28 \pm 0.55$ & $7.48 \pm 0.86$ \\
$1 \mathrm{mg} / \mathrm{kg} \mathrm{5-FU}$ & 6 & $13.50 \pm 0.94$ & $22.44 \pm 2.05$ & $26.34 \pm 2.33$ & $5.46 \pm 0.67$ \\
\hline
\end{tabular}

\section{Pro-apoptotic effects of VB in CRC xenograft tumors}

To investigate the tumor inhibitory activity of VB for $\mathrm{CRC}$, we first established a human CRC xenograft mode in mice, which were then treated with different doses of VB. In vivo data showed that VB remarkably inhibited growth of the xenografted tumors (Figure $2 \mathrm{~A}$ and $\mathrm{B}$ ).

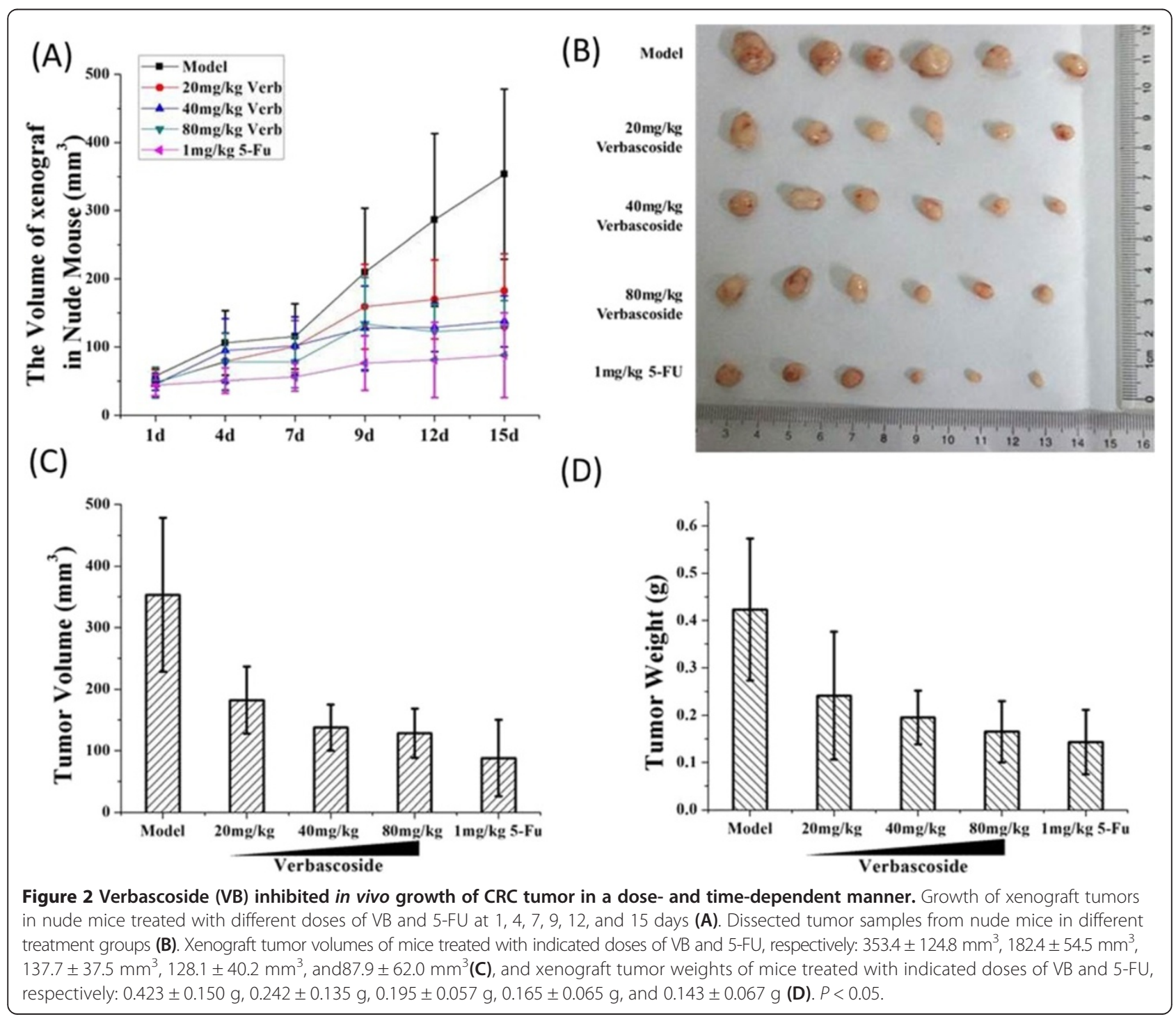


Tumor volume inhibition rates in the low-, medium-, and high-VB dose groups were $48.41 \%, 61.04 \%$, and $63.75 \%$, respectively; and tumor weight inhibition rates were 42.79\%, 53.90\%, and 60.99\%, respectively (Figure 2C, D). Notably, at higher doses, the anti-tumor effect of VB was similar to that of 5-FU (Figure 2). The VB-treated tumor samples were then analyzed by IHC for levels of apoptosis-related proteins such as HIPK2, p53, Bax, and $\mathrm{Bcl}-2$. The results indicated that VB significantly enhanced expression of pro-apoptotic HIPK2, p53, and Bax proteins in tumors, but decreased expression of anti-apoptotic protein Bcl-2, in a dose-dependent manner (Table 3, Figure 3).

\section{In vitro inhibitory effect of VBon CRC cells}

We next tested whether VB affected in vitro growth of CRC cell lines. After 24, 48, and 72 h of VB treatment, the growth of CRC cells HCT-116, LoVo, HT-29, and SW620 was dramatically inhibited, in a time- and dosedependent manner, with an $\mathrm{IC}_{50}$ of $29-67 \mu \mathrm{M}$ after $72 \mathrm{~h}$ (Figure 4).

\section{VB promoted apoptosis via p53 in human CRC cells}

Based on the cell proliferation inhibition data, we selected 48-htreatment of CRC HCT-116 and HT-29 as the optimal time frame for apoptosis experiments. We used drug doses of 25,50 , and $100 \mu \mathrm{M}$ of $\mathrm{VB}$ to treat cells for $48 \mathrm{~h}$ (Figure 5A, B), and used FITC Annexin-V/PI method to measure apoptosis induced by VB. Our data showed the apoptosis rate to be significantly increased by $\mathrm{VB}$ in a dose-dependent manner (Figure $5 \mathrm{C}$ ). Interestingly, this pro-apoptotic effect by VB was countered by a p53specific inhibitor, FPT-a (Figure 5D). This suggests that VB promotes apoptosis in CRC cells through ap53-dependent mechanism.

\section{VB promotes apoptosis in human CRCviaHIPK2-p53signaling pathway}

We next determined if expression levels of apoptosisrelated proteins changed in VB-treated human CRC cells HCT-116 and HT-29. We found, after $48 \mathrm{~h}$ of treatment, VB increased protein expression of HIPK2, p53, p-p53,

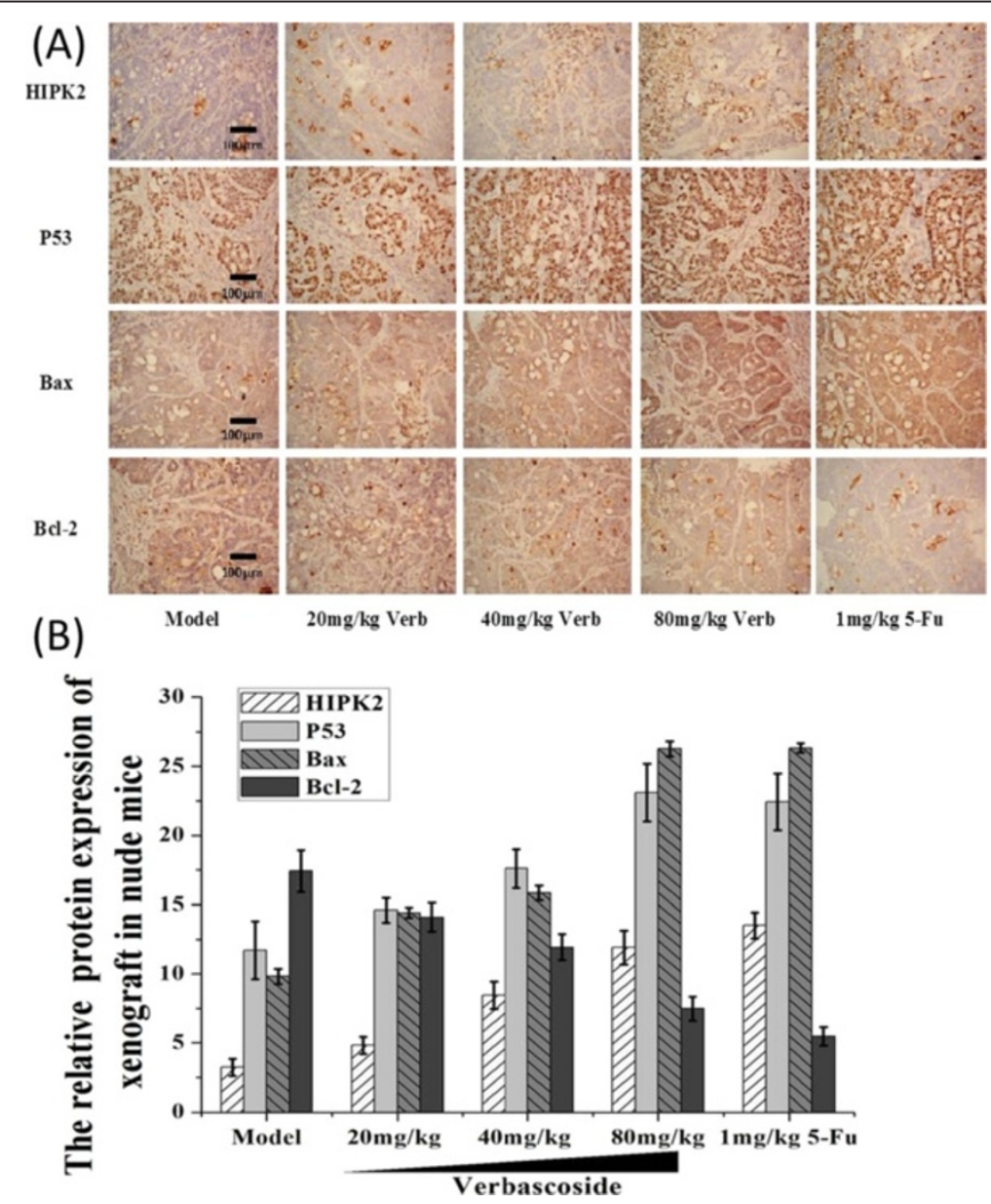

Figure 3 Expression of apoptosis-related proteins is affected by Verbascoside (VB) in CRC xenograft tumors. IHC staining of HIPK2, p53, $\mathrm{Bax}$, and $\mathrm{BCl}-2$ proteins in tumors treated with VB (A). Relative protein expression levels in (A) were quantified by image analysis software (B). Magnification $\times 200$. 


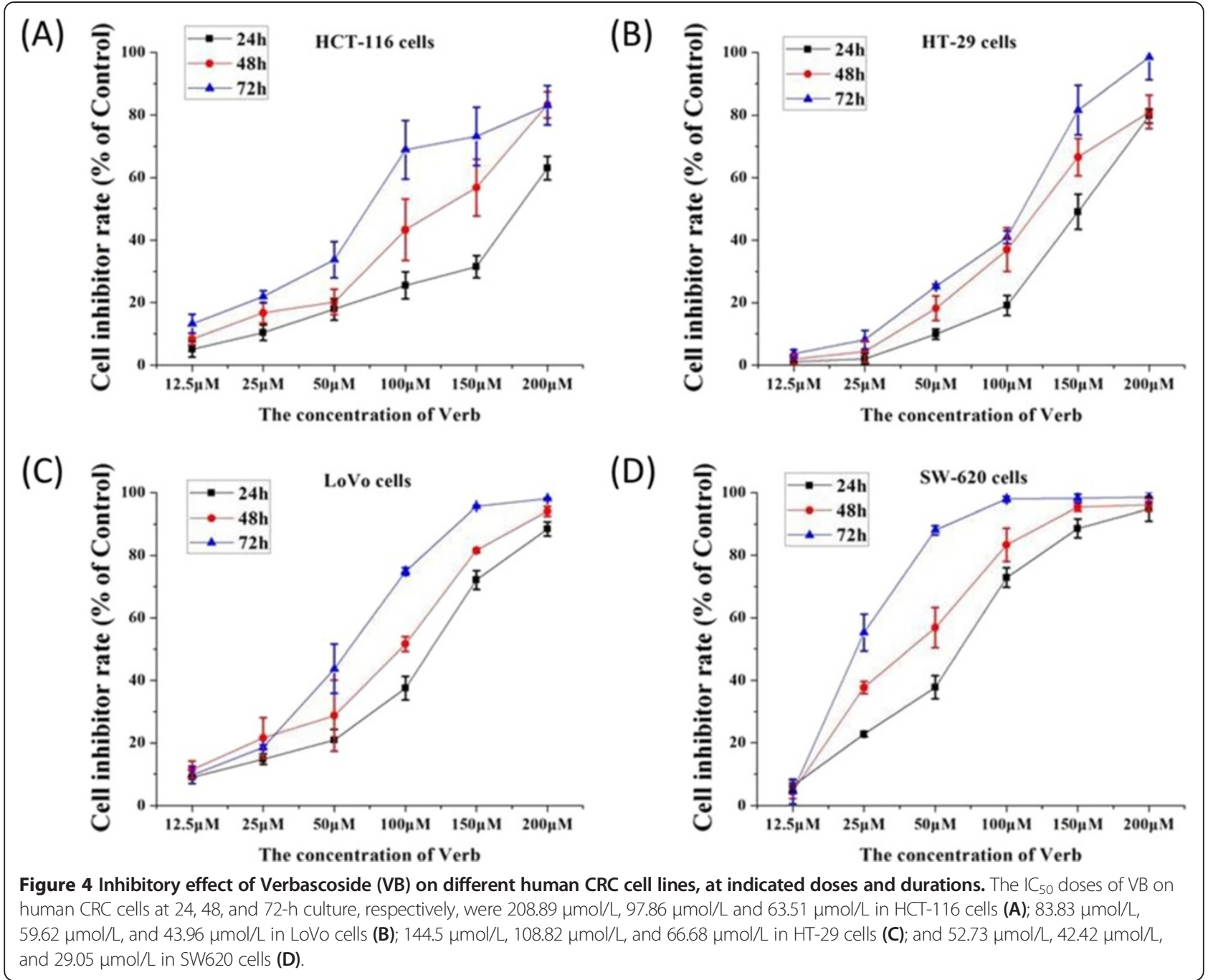

and Bax, but decreased that of Bcl-2, in a dose-dependent manner in the CRC cell lines (Figure 6A). These data both recapitulated the results we saw in the VB-treated CRC tumors in vivo, and further indicated that $\mathrm{VB}$ promotes apoptosis in CRC, probably through HIPK2-p53signaling axis. To verify this point, we added the p53-specific inhibitor PFT-a to the treated cells along with VB. The results showed that PFT-a rescued the cells from VB-induced apoptosis, by reducing VB-enhanced protein levels of p-p53 on Ser46, Bax, and restoring Bcl-2 protein expression, but did not affect HIPK2 protein levels (Figure 6B). These findings strongly suggest that VB-induced apoptosis is mediated by the HIPK2-p53signaling pathway.

\section{Discussion}

Apoptosis is a response of cells to internal and external signals under certain physiological and pathological circumstances, to maintain homeostasis [21]. Many anticancer drugs attack tumors by triggering apoptosis [22]. Mechanisms of drug-induced tumor apoptosis include altering cell signaling pathways, expression levels of tumor-suppressor oncogene products, and influencing other apoptosis-promoting and -inhibiting proteins. Anti-cancer drugs can also block the cell cycle and inhibit cell growth, while activating caspase cascades and modulating telomerase expression and activity [23-25].

As a newly found auxiliary transcription inhibition factor, HIPK2 has been suggested to affect many aspects of cancer. Studies showed that HIPK2 participates in a variety of signal transduction pathways, including p53 [26], Wnt/ק-catenin [27], JNK [28], and hypoxiainducible factor $[11,29,30]$. Recent studies suggest that HIPK2 influences apoptosis through a variety of mechanisms, especially the p53-mediated apoptosis signaling cascade $[19,20] . p 53$ is the most important tumor-suppressor gene, and is implicated in regulation of apoptosis; its protein is activation is controlled by post-translational modifications, such as phosphorylation, acetylation, and interactions with other proteins. p53 phosphorylation not only stabilizes and enhances the transcription activity of $\mathrm{p} 53$, but also regulates 


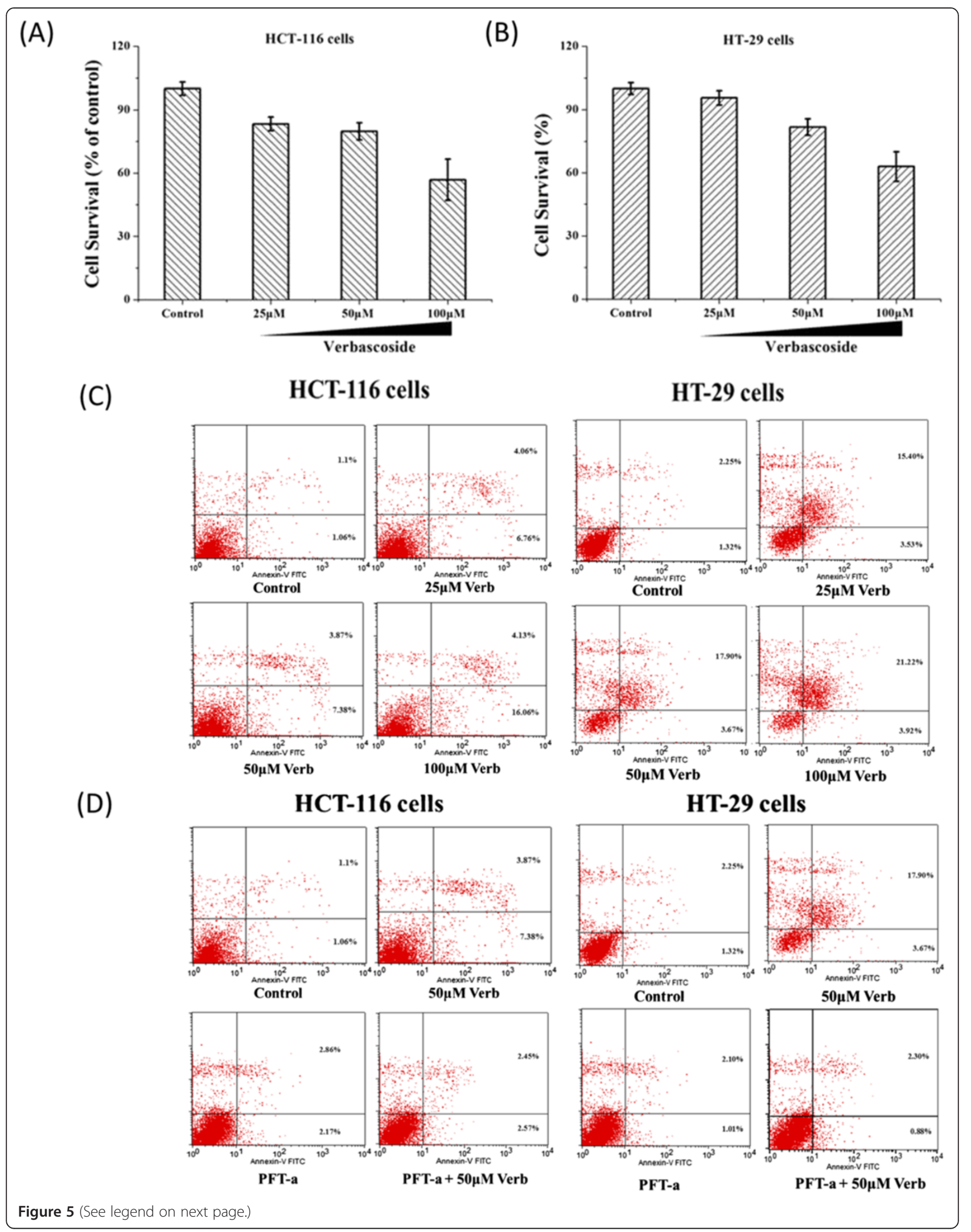


(See figure on previous page.)

Figure 5 Verbascoside (VB) promoted apoptosis via p53 in human CRC cells. CRC HCT-116 and HT-29 cells were treated by VB at indicated doses and duration, and then analyzed for apoptosis by flow cytometry. Inhibition at 25, 50, and $100 \mu \mathrm{M}$ of VB to HCT-116 cells was $20.20 \pm 4.08 \%$, $43.28 \pm 9.80 \%$, and $56.79 \pm 9.11 \%$ (A), and HT-29 cells, $4.36 \pm 3.39 \%, 18.22 \pm 3.94 \%$, and $37.01 \pm 6.98 \%$, respectively (B). HCT-116 apoptosis rate after being treated with 25,50 , and $100 \mu \mathrm{M}$ of $\mathrm{VB}$ was $10.83 \pm 1.28 \%, 11.25 \pm 1.54 \%$, and $20.19 \pm 2.8 \%$, and the HT-29 apoptosis rate, $18.92 \pm 6.12 \%$, $21.57 \pm 4.05 \%$, and $25.14 \pm 6.73 \%$, respectively (C). HCT-116 and HT-29 apoptosis rate was $11.25 \pm 1.54 \%$ and $21.57 \pm 4.05 \%$ after being treated with $50 \mu \mathrm{M}$ Verbascoside; and $5.03 \pm 2.77 \%$ and $3.11 \pm 1.16 \%$ after being treated with FPT-a (p53-specific inhibitor); and $5.02 \pm 0.73 \%$ and $3.18 \pm 1.82 \%$ after being treated with FPT-a and $50 \mu \mathrm{M}$ VB respectively (D).

its subcellular localization. p53 serine (Ser46) phosphorylation is critical to transcription of apoptosis-related genes. HIPK2 overexpression stabilizes and activatesp53 and promotes its binding to form the HIPK2-p53 complex, leading to Ser46 phosphorylation and increased apoptosis [31].

We conducted a retrospective analysis on 100 primary CRC tumor samples, and found that the average age of CRC diagnosis was $67.25 \pm 11.91$ years, which did not significantly vary by sex. Common symptoms of CRC include changes in bowel habits, hemafecia/melena, and abdominal pain or discomfort. Among them, hemafecia is the most common symptom, seen in $93.75 \%$ of patients with CRC. As for the clinicopathological features, the average tumor diameter was $5.31 \pm 2.21 \mathrm{~cm}$, with glandular cancer as the most common histology (91\%), and ulcerative type as the major morphological type (37\%). IHC analyses showed HIPK2 expression in normal colorectal mucosal tissues to be higher than in CRC samples. These data are consistent with previous reports showing a similar pattern for HIPK2 expressions in breast cancer and thyroid cancer [32-34]. Correlation analysis showed that HIPK2 expression was closely associated with Dukes staging and infiltration degrees, but not to sex, age, degree of differentiation, or lymph node metastasis.

We next tested VB's anti-tumor activity in an in vivo mouse model of human $\mathrm{CRC}$, and found VB to significantly inhibit xenograft tumor growth. IHC analyses showed heightened levels of pro-apoptotic proteins HIPK2, p53,

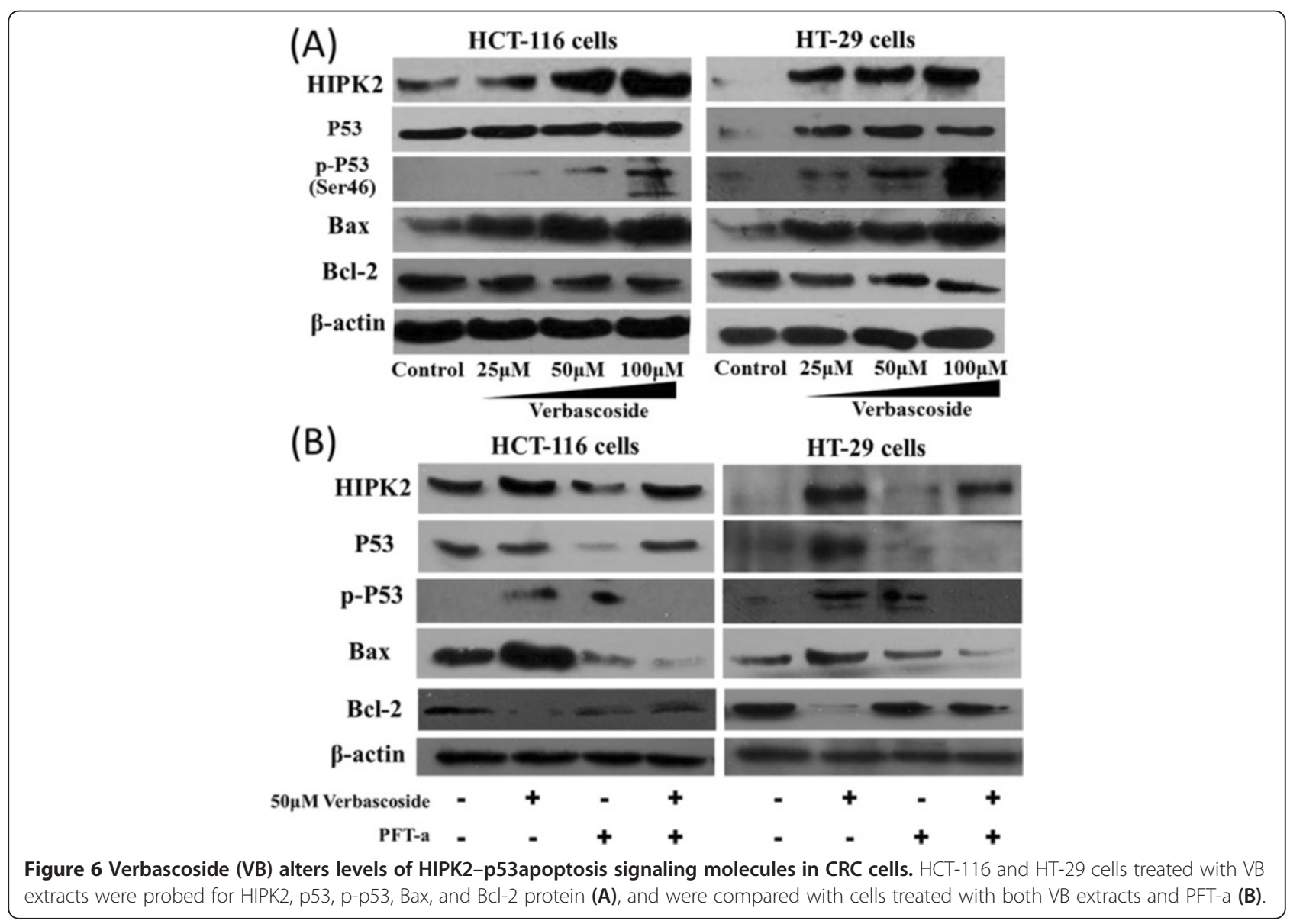


Bax, and decreasedBcl-2 in VB-treated tumors. These results imply that VB promotes cancer cellapoptosis throughHIPK-2- and p53-related signaling. To study the mechanisms of this anti-cancer effect, we used VB to treat human CRC cell lines. As with the in vivo studies, VB had a remarkable anti-proliferative and apoptosispromoting effect in HCT-116, HT-29, LoVo, and SW620 cells, in a time- and dose-dependent manner. In addition, this nicely correlates with the previous finding that VB induces genotoxic stress [35].

Reportedly, theHIPK2-p53 apoptotic pathway is downregulated in different human cancer cells [36-42]. In investigating the mechanisms that underpin VB-promoted apoptosis, we first learned that both in CRC tumors and cells, VB elevated HIPK2 protein levels. Additionally, levels of p53, p-p53 at Ser46, and downstream proapoptosis Bax protein were greatly boosted, whereas anti-apoptosis $\mathrm{Bcl}-2$ protein expression was reduced, by VB treatment. Furthermore, the pro-apoptotic action of VB was obscured by a p53-specific inhibitor, which restored protein levels of p-p53 (Ser46), p53, Bax, and Bcl-2 to the untreated status. Interestingly, HIPK2 protein expression was not influenced. To summarize, our data suggest that VB promotes 553 phosphorylation and Bax expression and inhibits $\mathrm{Bcl}-2$ expression by increasing HIPK2 levels in CRC, which leads to activation of theHIPK2-p53 signaling pathway and increased apoptosis.

\section{Conclusions}

In summary, we found that HIPK2 expression inversely correlates with primary CRC, Dukes staging, and infiltration degrees. We also found that VB significantly inhibits CRC growth in vivo, and represses CRC cell proliferation, and promotes apoptosis, by modulating the HIPK2-p53 signaling pathway.

\section{Competing interests}

The authors declare that they have no competing interests.

\section{Authors' contributions}

$\mathrm{QL}$ and $\mathrm{LZ}$ designed the overall program. LZ designed the in vivo experiments. XC performed most of the in vitro experiments with help from $Y F, Y J, X L, F H$, and QJ. HS, YW, and NL performed the in vivo experiments. $H S$, LZ, and QL wrote the manuscript, which was then reviewed and approved by all other authors.

\section{Acknowledgments \\ This study is supported by the National Natural Science Foundation of China (No.81303106), the Science Foundation for Shanghai Committee of Science Project (Nos.13140902500, 13ZR1462200), the Shanghai Health Bureau Science Foundation (No.20124048), and the Shanghai Municipal Education Commission (Nos. 12YZ058, 12ZZ118).}

\section{Author details}

'Department of Medical Oncology, Shuguang Hospital, Shanghai University of Traditional Chinese Medicine, Shanghai 201203, China. ${ }^{2}$ Cancer Institute and Longhua Hospital, Shanghai University of Traditional Chinese Medicine, Shanghai 200032, China.
Received: 6 January 2014 Accepted: 26 September 2014

Published: 5 October 2014

\section{References}

1. Jemal A, Bray F, Center MM, Ferlay J, Ward E, Forman D: Global cancer statistics. CA Cancer J Clin 2011, 61:69-90.

2. Liu EJ, Xiang YB, Jin F, Zhou SZ, Sun L, Fang RR, Yuan ZX, Gao LF, Gao YT: Cancer incidence trends in urban Shanghai, 1972-1999. Tumor 2004, 24:11-15.

3. Shanghai Municipal Center for Disease Control \& Prevention: Cancer incidence of Shanghai, 2009. Shanghai J Prev Med 2013, 25:54-55.

4. Wang Y, Debatin KM, Hug H: HIPK2 overexpression leads to stabilization of $\mathrm{p} 53$ protein and increased $\mathrm{p} 53$ transcriptional activity by decreasing Mdm2 protein levels. BMC Mol Biol 2001, 2:8.

5. Di Stefano V, Rinaldo C, Sacchi A, Soddu S, D'Orazi G: Homeodomaininteracting protein kinase-2 activity and p53 phosphorylation are critical events for cisplatin- mediated apoptosis. Exp Cell Res 2004, 293:311-320.

6. Nardinocchi L, Puca R, Givol D, D'Orazi G: HIPK2-a therapeutical target to be (re) activated for tumor suppression: role in p53 activation and HIF-1a Inhibition. Cell Cycle 2010, 9:1270-1275.

7. Puca R, Nardinocchi L, D'Orazi G: Regulation of vascular endothelial growth factor expression by homeodomain-interacting protein kinase-2. $J$ Exp Clin Cancer Res 2008, 27:1-7.

8. Li Z, Hu S, Wang J, Cai J, Xiao L, Yu L, Wang Z: MiR-27a modulates MDR1/P-glycoprotein expression by targeting HIPK2 in human ovarian cancer cells. Gynecol Oncol 2010, 119:125-130.

9. Kim EJ, Park JS, Um SJ: Identification and characterization of HIPK2 interacting with $p 73$ and modulating functions of the p53 family in vivo. J Biol Chem 2002, 277:32020-32028.

10. Puca R, Nardinocchi L, Gal H, Rechavi G, Amariglio N, Domany E, Notterman DA, Scarsella M, Leonetti C, Sacchi A, Blandino G, Givol D, D'Orazi G: Reversible dysfunction of wild-type 553 following homeodomain-interacting protein kinase-2 knockdown. Cancer Res 2008, 68:3707-3714.

11. Puca R, Nardinocchi L, Sacchi A, Rechavi G, Givol D, D'Orazi G: HIPK2 modulates p53 activity towards pro-apoptotic transcription. Mol Cancer 2009, 8:85.

12. McDonough $\mathrm{H}$, Charles $\mathrm{PC}$, Hilliard EG, Qian SB, Min JN, Portbury A, Cyr DM, Patterson C: Stress-dependent Daxx-CHIP interaction suppresses the p53 apoptotic program. J Biol Chem 2009, 284:20649-20659.

13. Obied HK, Prenzler PD, Konczak I, Rehman AU, Robards K: Chemistry and bioactivity of olive biophenols in some antioxidant and antiproliferative in vitro bioassays. Chem Res Toxicol 2009, 22:227-234.

14. Quirantes-Piné R, Zurek G, Barrajón-Catalán E, Bäßmann C, Micol V, Segura-Carretero A, Fernández-Gutiérrez A: A metabolite-profiling approach to assess the uptake and metabolism of phenolic compounds from olive leaves in SKBR3 cells by HPLC-ESI-QTOF-MS. J Pharm Biomed Anal 2013, 72:121-126.

15. Harput US, Genc Y, Saracoglu I: Cytotoxic and antioxidative activities of Plantago lagopus L. and characterization of its bioactive compounds. Food Chem Toxicol 2012, 50:1554-1559.

16. Kirmizibekmez H, Ariburnu E, Masullo M, Festa M, Capasso A, Yesilada E, Piacente S: Iridoid, phenylethanoid and flavonoid glycosides from Sideritis trojana. Fitoterapia 2012, 83:130-136.

17. Funari CS, Passalacqua TG, Rinaldo D, Napolitano A, Festa M, Capasso A, Piacente S, Pizza C, Young MC, Durigan G, Silva DH: Interconverting flavanone glucosides and other phenolic compounds in Lippia salviaefolia Cham. ethanol extracts. Phytochemistry 2011, 72:2052-2061.

18. Esposito E, Dal Toso R, Pressi G, Bramanti P, Meli R, Cuzzocrea S: Protective effect of verbascoside in activated $\mathrm{C} 6$ glioma cells: possible molecular mechanisms. Naunyn Schmiedebergs Arch Pharmacol 2010, 381:93-105.

19. Dauth I, Krüger J, Hofmann TG: Homeodomain-interacting protein kinase 2 is the ionizing radiation-activated $p 53$ serine 46 kinase and is regulated by ATM. Cancer Res 2007, 67:2274-2279.

20. Winter M, Sombroek D, Dauth I, Moehlenbrink J, Scheuermann K, Crone J, Hofmann TG: Control of HIPK2 stability by ubiquitin ligase Siah-1 and checkpoint kinases ATM and ATR. Nat Cell Biol 2008, 10:812-824.

21. Yao J, Qian CJ, Ye B, Zhang X, Liang Y: ERK inhibition enhances TSA-induced gastric cancer apoptosis via NF-KB-dependent and Notch-independent mechanism. Life Sci 2012, 91:186-193. 
22. Gangemi G, Gazzerro P, Fiore D, Proto MC, Butini S, Gemma S, Casagni A, Laezza C, Vitale M, Ligresti A, Di Marzo V, Zisterer DM, Nathwani S, Clive Williams D, Campiani G, Bifulco M: PBOX-15 induces apoptosis and improves the efficacy of oxaliplatin in human colorectal cancer cell lines. Eur J Pharmacol 2013, 714:379-387.

23. Cheng TC, Lu JF, Wang JS, Lin LJ, Kuo HI, Chen BH: Antiproliferation effect and apoptosis mechanism of prostate cancer cell PC-3 by flavonoids and saponins prepared from Gynostemma pentaphyllum. J Agric Food Chem 2011, 59:11319-11329.

24. Pongjit K, Chanvorachote P: Caveolin-1 sensitizes cisplatin-induced lung cancer apoptosis via superoxide anion-dependent mechanism. Mol Cell Biochem 2011, 358:365-373.

25. Du WW, Yang BB, Yang BL, Deng Z, Fang L, Shan SW, Jeyapalan Z, Zhang Y, Seth A, Yee AJ: Versican G3 domain modulates breast cancer apoptosis: a mechanism for breast cancer cell response to chemotherapy and EGFR therapy. PLoS One 2011, 6:e26396.

26. Puca R, Nardinocchi L, Starace G, Rechavi G, Sacchi A, Givol D, D'Orazi G. Nox 1 is involved in $\mathrm{p} 53$ deacetylation and suppression of its transcriptional activity and apoptosis. Free Radic Biol Med 2010, 48:1338-1346.

27. Kim EA, Kim JE, Sung KS, Choi DW, Lee BJ, Choi CY: Homeodomaininteracting protein kinase 2 (HIPK2) targets beta-catenin for phosphorylation and proteasomal degradation. Biochem Biophys Res Commun 2010, 394:966-971.

28. Hofmann TG, Stollberg N, Schmitz ML, Will H: HIPK2 regulates transforming growth factor-beta-induced c-Jun $\mathrm{NH}$ (2)-terminal kinase activation and apoptosis in human hepatoma cells. Cancer Res 2003 63:8271-8277.

29. Nardinocchi L, Puca R, Guidolin D, Belloni AS, Bossi G, Michiels C, Sacchi A, Onisto M, D'Orazi G: Transcriptional regulation of hypoxia-inducible factor 1alpha by HIPK2 suggests a novel mechanism to restrain tumor growth. Biochim Biophys Acta 2009, 1793:368-377.

30. Nardinocchi L, Puca R, Sacchi A, Rechavi G, Givol D, D'Orazi G: Targeting hypoxia in cancer cells by restoring homeodomain interacting protein-kinase 2 and p53 activity and suppressing HIF-1alpha. PLoS One 2009, 4:e6819.

31. D'Orazi G, Cecchinelli B, Bruno T, Manni I, Higashimoto Y, Saito S, Gostissa M, Coen S, Marchetti A, Del Sal G, Piaggio G, Fanciulli M, Appella E, Soddu S: Homeodomain-interacting protein kinase-2 phosphorylates p53 at Ser 46 and mediates apoptosis. Nat Cell Biol 2002, 4:11-19.

32. Nodale C, Sheffer M, Jacob-Hirsch J, Folgiero V, Falcioni R, Aiello A, Garufi A, Rechavi G, Givol D, D'Orazi G: HIPK2 downregulates vimentin and inhibits breast cancer cell invasion. Cancer Biol Ther 2012, 13:198-205.

33. Wesierska-Gadek J, Schmitz ML, Ranftler C: Roscovitine-activated HIP2 kinase induces phosphorylation of wt p53 at Ser-46 in human MCF-7 breast cancer cells. J Cell Biochem 2007, 100:865-874.

34. Lavra L, Rinaldo C, Ulivieri A, Luciani E, Fidanza P, Giacomelli L, Bellotti C, Ricci A, Trovato M, Soddu S, Bartolazzi A, Sciacchitano S: The loss of the p53 activator HIPK2 is responsible for galectin-3 overexpression in well differentiated thyroid carcinomas. PLoS One 2011, 6:e20665.

35. Santoro A, Bianco G, Picerno P, Aquino RP, Autore G, Marzocco S, Gazzerro P, Lioi MB, Bifulco M: Verminoside- and verbascoside-induced genotoxicity on human lymphocytes: involvement of PARP-1 and p53 proteins. Toxicol Lett 2008, 178:71-76

36. Hofmann TG, Möller A, Sirma H, Zentgraf H, Taya Y, Dröge W, Will H, Schmitz ML: Regulation of p53 activity by its interaction with homeodomain-interacting protein kinase-2. Nat Cell Biol 2002, 4:1-10.

37. Li Q, Lin S, Wang X, Lian G, Lu Z, Guo H, Ruan K, Wang Y, Ye Z, Han J, Lin SC: Axin determines cell fate by controlling the p53 activation threshold after DNA damage. Nat Cell Biol 2009, 11:1128-1134.

38. Crone J, Glas C, Schultheiss K, Moehlenbrink J, Krieghoff-Henning E, Hofmann TG: Zyxin is a critical regulator of the apoptotic HIPK2-p53 signaling axis. Cancer Res 2011, 71:2350-2359.

39. Gresko E, Roscic A, Ritterhoff S, Vichalkovski A, del Sal G, Schmitz ML: Autoregulatory control of the p53 response by caspase-mediated processing of HIPK2. EMBO J 2006, 25:1883-1894.

40. Bitomsky N, Conrad E, Moritz C, Polonio-Vallon T, Sombroek D, Schultheiss K, Glas C, Greiner V, Herbel C, Mantovani F, del Sal G, Peri F, Hofmann TG: Autophosphorylation and Pin 1 binding coordinate DNA damage-induced HIPK2 activation and cell death. Proc Natl Acad SCi US A 2013, 110:E4203-E4212.
41. Kumar N, Wethkamp N, Waters LC, Carr MD, Klempnauer KH: Tumor suppressor protein Pdcd4 interacts with Daxx and modulates the stability of Daxx and the Hipk2-dependent phosphorylation of p53 at serine 46. Oncogene 2013, 2:e37.

42. Mao JH, Wu D, Kim IJ, Kang HC, Wei G, Climent J, Kumar A, Pelorosso FG, Del Rosario R, Huang EJ, Balmain A: HIPK2 cooperates with p53 to suppress $\gamma$-ray radiation-induced mouse thymic lymphoma. Oncogene 2012, 31:1176-1180.

doi:10.1186/1471-2407-14-747

Cite this article as: Zhou et al:: Verbascoside promotes apoptosis by regulating HIPK2-p53 signaling in human colorectal cancer. BMC Cancer 2014 14:747.

\section{Submit your next manuscript to BioMed Central and take full advantage of:}

- Convenient online submission

- Thorough peer review

- No space constraints or color figure charges

- Immediate publication on acceptance

- Inclusion in PubMed, CAS, Scopus and Google Scholar

- Research which is freely available for redistribution 